\title{
Mangroves Among Most Carbon-rich Ecosystem Living in Hostile Saline Rich Environment and Mitigating Climate Change - A Case of Abu Dhabi
}

\author{
Tareefa S. Alsumaiti ${ }^{1 *} \bullet$ Shabbir A. Shahid ${ }^{2}$
}

\author{
${ }^{1}$ Assistant Professor, Geography and Urban Planning Department, College of Humanities and Social Sciences, United Arab \\ Emirates University, PO Box 15551 Alain, UAE. \\ ${ }^{2}$ Senior Soil and Climate Change Expert Freelancer, UAE. \\ *Corresponding author. E-mail: tareefa@uaeu.ac.ae
}

Accepted $3^{\text {rd }}$ January, 2019.

\begin{abstract}
This study provides an overview of mangrove forestations in Abu Dhabi and its numerous environmental benefits including the sequestering of atmospheric carbon dioxide (CO2) and climate change mitigation. It describes the efforts to increase mangrove plantation and the site selection criteria for mangrove establishment in the coastal land. It also discusses the natural regeneration and propagation of mangroves through seeds and seedlings, and the favorable conditions for the trees to reproduce and grow. Furthermore, the study describes the adaptation and occurrences of mangroves worldwide and in Abu Dhabi, the main anthropogenic and natural threats to mangroves ecosystems, and some of the biological \& physiological characteristics of mangrove trees such as the aerial roots "pneumatophore" and the salts glands that assist the trees to survive the harsh climate conditions. Finally, the study also highlights the importance of mangroves in climate change mitigation, carbon sequestration, and coastline protection. The valuable information presented can help in managing and preserving this unique ecosystem and support climate change mitigation and adaptation, and achieve environmental sustainability.
\end{abstract}

Keywords: Mangroves, physiological functions, climate change mitigation, carbon sequestering, site selection, regeneration, benefits, threats.

\section{Introduction}

Mangroves are one of the various types of littoral trees that mostly inhabit the sheltered coastlines within the intertidal zone of tropical and subtropical regions near the equator. Mangrove forests are among the most productive ecosystems, and they form a crucial part of the coastal ecosystem in the world (Food and Agricultural Organization of the United Nations (FAO, 2007). Mangroves unlike conventional terrestrial plants are salt tolerant, live in shallow tidal waters and hostile environment rich in salinity and against sea wave currents. Mangroves has special biological and physiological functions that support its survival under very hostile saline environment, such as the aerial roots "pneumatophores" and the salts glands (Medina, 1999). Mangroves grow very well where habitats are rich in organic matter, clay and mineral contents. It also grows very well when habitats are intertidal mud flats and subject to regular tidal coverage. About $75 \%$ of world's mangroves are found in 15 countries only, and just $6.9 \%$ of total mangrove area are protected (Giri et al., 2010). Mangroves are associated with several environmental benefits such as the sequestering of atmospheric carbon dioxide (CO2) and coastline protection. Mangroves are among the most carbon-rich forests in the tropics. They 
can store and sequester carbon much faster than any tropical forests on the earth and lowers greenhouse gases. However, activities such as the increase in the human population, anthropogenic activities, and global warming, pose major threats on mangrove forests which puts mangroves at a risk of extinction. Mangroves are facing many threats such as landfilling, dredging, foreshore construction, tidal obstruction and groundwater extraction (Alsumaiti et al., 2017).

Mangrove forests are national treasures of the United Arab Emirates and other arid countries with limited forested areas. The importance of mangroves leads to an increase in research from various perspectives. The literature of mangrove forests is extensive with the existence of numerous case studies about mangroves all over the world; however, mangrove studies in arid regions, such as the Arabian Gulf region has been lacking. Thus, the primary purpose of this paper is to address mangrove ecosystems in Abu Dhabi. In addition, the science behind mangroves is described in this study in terms of their propagation, establishment, adaptations, threats, benefits, climate change mitigation, and sustainability. This valuable information can help in managing and preserving this unique ecosystem and support climate change mitigation and adaptation since carbon sequestration by mangroves is one of their main ecosystem services.

\section{Mangroves forestation in Abu Dhabi}

Abu Dhabi Emirate is one of the seven emirates making the federation of The United Arab Emirates (UAE). It is located between latitudes $22^{\circ} 40$ and around $25^{\circ}$ north and longitudes $51^{\circ}$ and around $56^{\circ}$ east. Its total area is $67,340 \mathrm{~km}^{2}$ and covers $87 \%$ of the total area of the UAE. Abu Dhabi climate is hyper-arid, with hot summers, warm winters, and scanty rainfall ( $<100 \mathrm{~mm} /$ annum) irregularly scattered during the year. Abu Dhabi has a very high potential evaporation rate (2-3 $\mathrm{mm} /$ day), a very low groundwater recharge ( $<4 \%$ of total annual water use), and no surface water resources (FAO, 2008). The main habitats of Abu Dhabi emirate coastal zone are mangroves dominant by Avicennia marina (grey mangroves), salt-marshes dominant by Arthrocnemum macrostachyum, tidal flats with cyanobacterial mats, sandy and rocky beaches, coastal flats and low sand dunes, sabkha, cliffs and rocky headlands (Alsumaiti et al., 2017).

Mangroves forestation in Abu Dhabi Emirate constitutes an important ecosystem. Mangroves and Mangal have two different meanings-mangrove (plant) and mangal (plant community and habitats where mangroves thrive). Historical record of Abu Dhabi shows that mangrove wood was a major source of food and fuel. Mangroves were also used for building houses and ships because of its durability and high resistance to rot and termites. Abu Dhabi Emirate hosts approximately 110 $\mathrm{km} 2$ of both natural and planted mangroves spread along 547 kilometers of shoreline, which provide a rich natural habitat and safe breeding ground for several fish species, sea snakes, turtles and commercially important shrimp, snapper, grunt fish and sea bream. Sea birds also find safe nesting and egg laying areas in the vast mangrove forests. Most of the mangroves forests are inaccessible owing to their location, and exception is for those in the coast (Rabanal and Beuschel, 1978). In addition to the Eastern Lagoon Mangrove National Park of Abu Dhabi that was opened to the public on October 1, 2014, there are vast areas of mangrove forests in Delma, Sir Bani Yas Island, Bu Tinah Island, Saadiyat Island, Abu Al Abyadh Island, Al Aryam Island and the Al Dhabeia islands of Abu Dhabi. Only one species of mangrove, Avicennia marina (Forssk.) Vierh. occurs in the Gulf region, while other species, Rhizophora mucronate Lam. disappeared in historical times (Alsumaiti et al., 2017).

Abu Dhabi Emirate is consistently making efforts to increase mangrove plantation. Recently the Environment Agency of Abu Dhabi (EAD) partnered with the Tourism Development and Investment Company (TDIC) to plant 750,000 saplings of mangroves on $25 \%$ of the Saadiyat island, which is currently being developed as a cultural hub of Abu Dhabi. The move is aimed at mitigating the environmental damages caused by the massive development on the island. Property developers are also urged to protect this endangered natural treasure by giving the environment proper consideration from the early planning stages of their development. The Environment Agency of Abu Dhabi (EAD) has also succeeded in reintroducing the mangrove species (Rhizophora mucronata) in the waters of Ras Ghanada Island after 100 years of its extinction. Evaluating the spatial distribution, the areal extent of mangrove forests has been a research priority in UAE due to the significant reduction in the forest area because of human and natural disturbances (Alsumaiti et al., 2017). Environmental factors including geomorphology, tidal range, and climate conditions tend to influence mangrove forests' productivity and distribution; some types of mangrove trees are more tolerant than others to variations in these environmental factors (Tam and Wong, 1998; English et al., 1997; Cintron et al., 1985). Notably, soil properties are one of the most important environmental factors that have a direct influence on mangrove structure, productivity, and distribution. Several researchers have examined the link between mangroves structure and various soil conditions. They found that the variations in trees' height and productivity are due to the temporal and spatial variation of soil properties such as soil salinity, soil nutrient availability and soil fertility (Feller et al., 2002; McKee, 1993). Therefore, it is salient to comprehend the soils' physical and chemical characteristics from mangrove plantation to evaluate vegetation structure (Boto and Wellington, 1984). 


\section{The Eastern Mangrove Lagoon National Park (EMLNP) of Abu Dhabi}

The naturally occurring mangroves (locally called 'AlQurm') in Abu Dhabi emirate belongs to species (Avicennia marina) and is considered grey mangroves due to the color of leaves underside. The EMLNP is the first protected mangrove area in Abu Dhabi and it covers approximately $7 \mathrm{~km}^{2}$. The EMLNP is home to around 60 bird species and supports other biodiversity such as fish, shells, sponges, shrimps, echinoderms, and crabs. The dense and complex structure of old natural stands provides a rich environment for fish and other species. Visitors to the EMLNP can enjoy bird watching, romantic sunset tours using the traditional "Abra", kayaking and paddle boarding. The average height of the trees is about three meters, but they can reach up to seven meters in some areas (Alsumaiti, 2014). Saenger et al. (2001) presented a brief overview of the mangroves in the Arabian Gulf and mangrove resources of UAE. Earlier estimates based on remote sensing presents $40 \mathrm{~km}^{2}$ mangroves in Abu Dhabi, of which $3 / 4$ are open mangroves and rest dense mangroves.

\section{Site selection criteria for mangrove establishment in the coastal land}

Very little has been published to evaluate the potential sites in the coast where mangroves can be established successfully. An attempt has been made in Kuwait (Shahid et al., 2004) to fill this gap partially but specific to Kuwait conditions. Ten point criteria was established to survey potential sites for final selection of sites to introduce mangroves. The site selection criteria includes, accessibility to site (for easy plantation) and inaccessibility to the grazers (to avoid mangrove damage by animals), texture of the mudflat (presence of slit and clay), topography (to drain tidal water back to sea rather than flat ground where the water stagnates, daily tidal coverage for regular flushing of salts), non-contaminated by debris (to protect young plants from damage), oil spills (oil contamination can cause hydrophobic conditions and heavy metals are not conducive) and drainage effluent (industrial effluent contain toxic chemicals, and continuous ponding of drainage water create anoxic conditions), and the site must have low salinity and without coastal shells (high shells pose difficulty for propagule establishment). Using the aerial photographs and the above selection criteria, five sites were selected in the coastline of Kuwait and mangroves were successfully planted (Bhat et al., 2004).

\section{Natural regeneration and propagation of mangroves through seeds and seedlings}

Mangroves grow in a modest temperature of not more than $35^{\circ} \mathrm{C}$ and low salinity water, making their survival a big challenge in Abu Dhabi, where temperatures rise during summer months. Mangroves are low scrubby plants, whereas under favorable conditions they can form majestic forests with canopy of over 10 meters tall, such as the mangroves forests of Abu Dhabi that are well established on tidal habitat. The mangroves are either planted or naturally regenerated. Natural establishment of seedlings from seeds is very critical. However, the establishment of mangrove seedlings can be very challenging due to the variable soil substrates and the tidal influence and floatation. All mangrove species produce buoyant seeds that float and disperse in water. Most of the mangroves are viviparous (ability of the seeds to germinate while still on the mother plant-before their detachment) and once propagules become mature, they separate from the mother plant and fall in the water. The propagules can survive desiccation and remain dormant from days or even up to one year, until lodged to conducive environment (mud) and starts growing. They can establish well in sediment with abundance of fines (silt \& clay) and organic matter to set their roots to protect from waves. Mangroves are found above sea level because the mud where they take root needs to be totally exposed, or free from inundation for some period each day (low tide), and under continuous inundation mangrove root system is unable to take oxygen. In an effort to describe ideal location for mangrove plantation in the coast, Shahid et al. (2004) described the criteria for the selection of best sites for the introduction of mangrove in Kuwait, which can be used in other countries where similar conditions may be existing especially in other GCC countries.

Mangroves seedlings can be initially raised in the nursery and when the propagules are ready, they can be planted in the coastal areas. Various researchers have published guidelines for raising mangrove container plants nurseries and mangrove plantation in UAE (Vistro, 2010), vegetative and micropropagation of mangroves in India (Eganathan and Rao, 2001) and growing mangroves in coastlines of Kuwait (Bhat et al., 2004; Bhat et al., 2007). Vegetative propagation is the fastest method raising the plants throughout the year, and plantable stock can be obtained easily compared to those raised through the seeds. Vegetative propagation (Eganathan and Rao, 2001) has certain advantages (single stock can produce large number of plants, maintain genetic uniformity, rapid, cheaper and easy commercialization) and disadvantages (not all species are amenable for this purpose, needs to standardize the method under set of environment conditions, old trees are hard to propagate compared to young trees). Vegetative propagation includes stem cutting (i.e., production of saplings from stem and branch cutting) and propagule cutting (hypocotyl-seed germinated in the mother tree before its detachment) and air layering (roots are produced in small branches by applying root producing hormones and rooting media). 
Raising the mangroves in containers (Vistro, 2010) includes collection of good quality seeds (healthy, disease free), mature trees can be collected between August and September, storage of seeds (Avicennia marina seeds can be stored for maximum of ten days, fully immersed in seawater), filling the pots with potting media (soil with organic fertilizer, i.e. potting mix, compost, poultry or cow dung as available), and seeding in containers (seed should be soaked in seawater for 24 hours to soften the seed coat and removing by hand). The seed germination starts after 7-8 days and completed in three weeks, and the plants reached a height of $30 \mathrm{~cm}$ in 5-6 months (producing 3-4 pairs of leaves). At this stage the seedlings can be transplanted at the selected site.

\section{Adaptation and occurrences of mangroves}

The world mangroves flora is represented by about 65 species. Mangroves, unlike conventional terrestrial plants live in hostile environment rich in salinity, anoxia conditions (a lack of oxygen in the continually waterlogged conditions) and against sea wave currents. Special physiological functions, like respiration by special roots "pneumatophores" under waterlogged conditions (Figure 1a), secretion of salts from glands (Figure 1b), absorption of high amount of water "succulence", and lack of competition with other plants to grow under such hostile saline environment are the unique advantages to mangrove growing in the coastline areas. Mangroves inhabit the intertidal mudflats, sheltered coastlines and lagoons and creeks. The total area of mangroves in the year 2000 was $137,760 \mathrm{~km}^{2}$ in 118 countries and territories in the tropical and subtropical regions of the world. Approximately $75 \%$ of world's mangroves are found in just 15 countries, and only $6.9 \%$ are protected under the existing protected areas network (IUCN I-IV) (Giri et al., 2010).

Mangroves afforestation in the intertidal mudflats may be a good strategy to develop green cover and enriching the marine ecosystem. Mangrove forests occur all around the world; exceptions are for the Europe, the Arctic and Antarctic, where low water temperature (less than $21^{\circ} \mathrm{C}$ ) conditions are not conducive for their establishment and growth. They require long days and high intensity sunlight for rapid growth and development, and the growth in winter is low due to reduced rate of photosynthesis by low light conditions. The optimum light intensity required for mangroves development is between 3,000-3,800 $\mathrm{kcal} / \mathrm{m}^{2} /$ day (Kato and Akarsone, 1998). The world largest and best mangrove forests "Sundarbans" are in Asia (India and Bangladesh). In Pakistan, mangrove forests occur in the Sindh province. In UAE, lush green mangroves (Avicennia marina) occur in the larger coastlines of Abu Dhabi emirate. In other emirates of the UAE, mangroves also exist but to a lesser extent. Abu
Dhabi mangrove swamps represent about half of the mangroves throughout the Arabian Gulf Region. Abu Dhabi Emirate has tidal lagoons, which account for over $70 \%$ of the natural mangrove forests in the UAE. Furthermore, mangrove forests are present between Ras Ghanada in the northeast to Marawah Island further west. Recently, Avicennia marina has been introduced in the coastline of Kuwait (Bhat et al., 2004). Mangrove establishment requires stable mudflats and special environmental conditions (Shahid et al., 2004). Rarely, they have been seen inland.

\section{Threats to mangroves ecosystems}

There are number of anthropogenic and natural threats to mangroves ecosystems. Fransworth and Ellison (1997), based on the global survey, has reported major anthropogenic threats as reclamation for settlements, agriculture and aquaculture, harvesting for forestry products (timber, wood-chip industry), sewage discharge, pollution and changes in hydrological regimes. There is scarce evidence of sewage discharge to impact mangroves, however, changes in microbial population and activities has been recorded (Tam et al., 1998). With regards to oil spills, mangroves are considered to be the most sensitive of all coastal ecosystem types (Snedaker et al., 2001; Hays and Gundlack, 1979). Besides human activities that threaten mangrove ecosystems, natural threats such as climate change have significant destructive effects on the growth of mangroves and their environment. The primary climate factors that affect mangrove forests include changes in sea-level, temperature, precipitation, $\mathrm{CO}_{2}$ concentration, and storms and hurricanes (Alsumaiti et al., 2017).

However, in Abu Dhabi, the major threats to mangroves includes, i) hydrological modification (due to landfilling, dredging, foreshore construction such as waterways and jetties, tidal obstruction and groundwater extraction); ii) short and long-term effect of hydrocarbons-oil and oil dispersant mixtures (Saenger et al., 2001), pollution (Shriadah, 1999) and urban expansion (EAD, 2011). Recently, efforts have been made for new mangrove plantation and to preserve the existing mangrove forests to keep the balance and coastal protection (Figure 1a).

\section{How mangroves cope with excess salts?}

It is well recognized that high salts are injurious to plants. The salinity tolerance of mangroves has been attracted by molecular biologists and physiologists because they form dynamic system involving plants, seawater, soils and marine fauna (Ogino, 1993). Mangroves accumulate salts which are compensated by salt secretion via salt glands, otherwise the salt is sequestered and can be voided only when the leaves eventually fall. Mangroves 


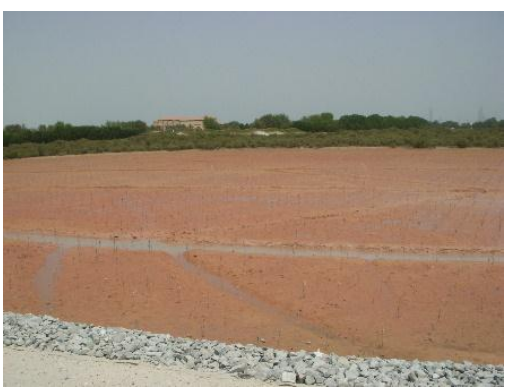

a) Mangrove plantation for coastal protection in Abu Dhabi

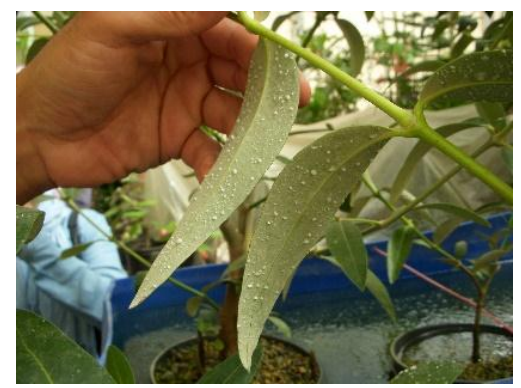

b) Salt secretion through salt-glands in Avicennia marina

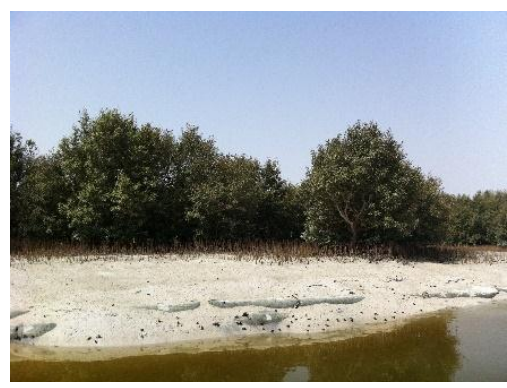

c) Special aerial roots "Pneumatophores"

Figure 1. New planation in Abu Dhabi coastal land (a); salts secretions from leaves underside (b); above ground appearance of special roots "pneumatophores" (c).

tolerate soil salinity through maintaining a high cellular water potential, succulence, and are relatively insensitive to salt toxicity. The salt tolerance involves various factors (ionic potential across membranes, osmotic relationships, enzyme activation, and protein synthesis). An extended discussion on salt tolerance is given by Waisel (1972) and Flowers et al. (1977). Mangrove plants have their physiological make up to exclude salts. Mangroves are one of these plants group, and are called "secretors" excluding salts metabolically via salt glands. The salt can crystallize by evaporation and either can be blown away or washed off (Shahid, 2012), whereas roots compared to leaves partially exclude salts. The most distinctive trichome in certain mangrove leaves is the structure that secretes solutions of certain ions, such as $\mathrm{Na}$ and $\mathrm{Cl}$ through salt glands (Fahn, 1979). In mangroves salts glands occur in Avicennia marina. Salt glands are abundant in leaves but are not necessarily equal on upper and lower surface, and the salts evaporate and crystallize in a conspicuous manner. However, it is not uncommon to see crystallized salts on the base of leaves (Figure 1b).

\section{Mangroves have special root structure - Pneumatophore}

Mangroves have several types of aerial roots. Part of the root system has specialized features of root system which is exposed (Figure 1c) to the atmosphere "aerial roots" (Gill and Tomlinson, 1975) at-least part of the day, that is, at low tide. However, these aerial roots are covered at high tide (Figure $2 a \& b$ ). The mangroves are grown in anaerobic conditions and there is need for atmospheric oxygenation, which is performed by aerial roots "pneumatophore" (respiratory or prop roots) protruding all around (Figure 1c), often many meters away from the trunk of the tree. The pneumatophores are actually breathing tubes or 'snorkels' covered by pores or lenticels, allowing oxygen transport within the plants. A survey of mangrove root system has been published by Troll (1943). In a descriptive term, any root which has direct upward extension or appendage of the subterranean root system is called "pneumatophore". These roots are pencil-like erect branches spaced on almost equal intervals along the first order roots. The pneumatophores remain unbranched, but are capable of branching, seemingly only when damaged. In Avicennia marina, surface of pneumatophores remain smooth and spongy and consist of chlorophyll in the subsurface layers.

\section{Climate change mitigation and carbon sequestration by mangrove ecosystems}

Mangroves are considered as carbon sinks because they store and sequester carbon much faster than tropical forests or any other ecosystem on the earth, thus lowers greenhouse gases. Mangrove like other plants capture $\mathrm{CO} 2$ during photosynthesis, thereby removing $\mathrm{CO} 2$ from the atmosphere.

Photosynthesis is a compound word made up of photo (which means "light") and synthesis (which means "to put together"). A process by which green plants and certain other organisms use the energy of light to convert carbon dioxide and water into the simple sugar glucose and oxygen.

The chemical formula is given below;

$$
\begin{aligned}
& \text { Carbon dioxide + Water + Light } \rightarrow \text { Glucose + Oxygen } \\
& 6 \mathrm{CO}_{2}+6 \mathrm{H}_{2} \mathrm{O}+\text { light energy }=\mathrm{C}_{6} \mathrm{H}_{12} \mathrm{O}_{6}+6 \mathrm{O}_{2}
\end{aligned}
$$

Mangroves are among the most carbon-rich forests in the tropics (Donato et al., 2011) containing on average 1,023 Megagrams carbon per hectare. Mangroves per hectare have the capacity to store carbon four times more than most other tropical forests around the world. A high carbon storing capacity is attributed partially to deep organic rich mud in which mangroves thrive, which is unique to mangrove ecosystem. Organic rich mud "settled due to special root system pneumatophores" where mangroves thrive, stores five times more carbon than temperate, boreal and tropical terrestrial forests on 


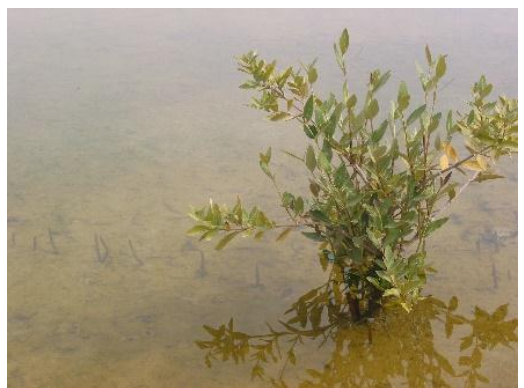

a) Young mangrove tree and pneumatophores under the tide

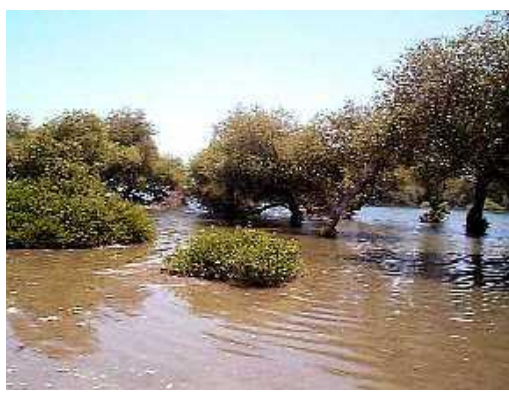

b) Eastern Mangrove Lagoon National Park at high tide

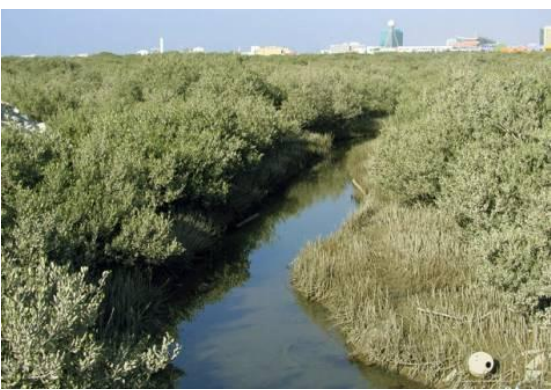

c) Intertidal creek in mangrove forest

Figure 2. Various features of Eastern Mangrove Lagoon National Park.

per unit area basis. Other reason of high carbon storage is due to less decomposition of organic matter under hypoxic conditions. Organic-rich soils ranged from $0.5 \mathrm{~m}$ to more than $3 \mathrm{~m}$ in depth and accounted for $49-98 \%$ of carbon storage in these systems (Van der Werf et al., 2009). Some view mangroves as not giving benefits like conventional forests, while others view is even if we negate all benefits of mangroves as forests, their value as protector of shorelines, enhancing aesthetic and recreational value, moderating climate is enough to convince us conserving them. The role of mangroves in sequestering climate-warming $\mathrm{CO}_{2}$ has not yet been widely investigated; perhaps such studies are not providing quick dollar value. The increase on $\mathrm{CO}_{2}$ level in the atmosphere will favor mangrove growth, but impact of global warming and aridity will decrease crop growth in general and many areas in agriculture may be eliminated "prolonged drought" with significant reduction in rainfall.

That is not the case in UAE, where mangrove forestation is considered a mean of climate change mitigation, marine ecosystem and coastal protection, and not from the perspective of dollar value. The Emirates' mangroves have a high ecological value to the Arabian Gulf (Saenger et al., 2001). Coastal vegetated mangroves are sensitive to climate change and long-term sea-level changes because their location is intimately linked to sea level. EAD $(2009,2013)$ conducted a Blue Carbon Demonstration project and found that, blue carbon ecosystems in Abu Dhabi are estimated to store over 41 million tonnes of carbon dioxide equivalent within the soil and biomass, and more than the Emirate's annual emissions from the oil and gas industry (26.4 million tonnes) or water and electricity (30.9 million tonnes) sectors.

\section{Mangroves cope the storm surges and coastline protection}

The coast being an important ecosystem requires implementation of an integrated coastal area management (ICAM) approach. The ICAM is the accepted framework for long-term planning, use, conservation and rehabilitation of coastal ecosystems. In this context, mangroves are considered key player in coastline protection, as well as buffer between land and the sea. The value of mangroves has long been recognized in protecting and improving coastal environment as well as enriching marine biodiversity. The mangroves have massive root system established in the mud and as exposure to the air "pneumatophores", the latter protects the coasts by dissipating energy of large waves and storm surges. Aside from crucial importance of mangroves for coastline protection, mangroves provide direct and indirect benefits under certain environmental conditions. An increase in storm extreme may cause severe erosion of the mudflats, around which mangroves thrive and subsequent irreversible coastal erosion (Alsumaiti et al., 2017; Alsumaiti and Shahid, 2018).

Clearance of coastal mangroves for urban expansion is enhancing the vulnerability of coastal infrastructures to climate change impact like rise in sea level, tidal affects and storm surges. They protect the coastline from the effect of wind and storm surges through the reduction of wave currents. When the Asian worst tsunami (26 December 2004, magnitude 9.0 on Richter scale) hit number of countries (India, Indonesia, Maldives, Myanmar, Sri Lanka and Thailand), the coastline behind the mangrove stretches were less affected, and reduced the causalities considerably. For example, Myanmar escaped from high damages and high number of casualties as the tsunami developed more in an east and west direction, and the mangrove forests protected the coastal zone (FAO-RAO, 2005). In Indonesia (Aceh), the tsunami destroyed 92,000 farms $(61,816$ ha agriculture area). However, mangroves cannot stop major disasters like tsunami, but, they can surely cushion the storm impact.

\section{Mangroves deforestation and consequences}

Mangroves are good sources of timber, fuel and fodder, as well as breeding and nursery grounds for many marine 
organisms and harboring invertebrates (epibenthic, infaunal, meiofaunal) including fish, amphibians, reptile and birds (aquatic and tree dwelling). Ironically, the great human tragedy of the recent December 26th 2004 tsunami may provide the stimulus for a better understanding of what mangrove forests can and cannot do for human well-being. Mangroves are strong candidates to mitigate climate change through reducing deforestation. The accurate and rapid method of monitoring mangrove deforestation is the use of world satellite imagery taken over many years; this provides comprehensive data on deforestation. The areal extent of mangrove forests has declined by $30-50 \%$ over the past half century because of coastal development, aquaculture expansion and over-harvesting (Alongi, 2002; FAO, 2007), and current annual loss rates vary from 1 to $20 \%$ (Alongi, 2002). Another estimate shows that at least $35 \%$ of the area of mangrove forests has been lost in the past two decades. The loss of mangrove area has exceeded those for tropical rain forests and coral reefs, two other well-known threatened environments. Carbon emissions from mangrove deforestation alone, contribute to $10 \%$ of carbon emissions from global deforestation. The mangrove deforestation generates emissions of $0.02-0.12 \mathrm{Pg}$ carbon per year-as much as around $10 \%$ of emissions from deforestation globally, despite accounting for just $0.7 \%$ of tropical forest area (Van der Werf et al., 2009). Plantation of new trees and preservation of forests is an important action we can take in response to global warming. Mangroves deforestation to obtain firewood or other uses enhances global warming. Some consider planting new mangroves in other places as a compromise to clearance, and hence questions their immediate value compared to when they will be fully established (the state when they were cleared).

\section{Conclusion and Recommendation}

This study has brought insight on the composition of the mangrove forest in Abu Dhabi and the importance of the forest in sequestering the atmospheric carbon dioxide (CO2) and mitigating climate change. It has described the main criteria for establishing mangrove plantation and locating new sites. It also discussed the natural regeneration and propagation of mangroves through seeds and seedlings and the favorable conditions for the trees to reproduce and grow. Furthermore, the study has described the adaptation and occurrences of mangroves worldwide and in Abu Dhabi. The great significance of the mangrove ecosystems is due to the fact that it connects the land and sea. It has also highlighted some of the benefits that can be derived from mangrove ecosystems. Even though they provide many benefits to society, mangrove forests are facing different threats. This vital ecosystem needs to be protected from both anthropogenic and natural threats. It is acknowledged that mangrove forests have been reduced to close to half the original population. Despite the existence of mangroves in several areas in Abu Dhabi, many people have no knowledge about the forests which increases the chances of encroachment. It is important that actions must be taken to increase public awareness regarding mangrove forests, and new environmental regulations to conserve the forests must be introduced. Additionally, it is very important to establish marine protected areas and increase total areas of mangrove through establishing mangrove plantations which are other significant approaches of enhancing the mangroves. Furthermore, different organization worldwide initiated intensive research to ensure continued survival of mangroves. However, there are gaps in our knowledge of understanding mangrove ecosystems as these forests remain poorly understood.

\section{REFERENCES}

Alongi DM (2002). Present and future of the world's mangrove forests, Environ. Conserv. 29(3), 331-349.

Alsumaiti TS (2014). An Assessment of Avicennia marina Forest Structure and Aboveground Biomass in Eastern Mangrove Lagoon National Park, Abu Dhabi. The Arab World Geographer. 17(2):166185

Alsumaiti TS, Shahid SA (2018). A Comprehensive analysis of mangrove soil in eastern lagoon National Park of Abu Dhabi Emirate. Int. J. Bus. Appl. Soc. Sci. 4(5):39-56.

Alsumaiti TS, Hussein K, Alsumaiti AS (2017). Mangrove of Abu Dhabi Emirate, UAE, in a Global Context: A Review. Int. J. Environ. Sci. 6(4):110-121. ISSN: 2277-1948.

Bhat NR, Suleiman MK, Shahid SA (2004). Mangroves, Avicennia marina, establishment and growth under the arid climate of Kuwait Arid Land Res. Manage. 18:127-139.

Bhat NR, Al-Nasser A, Suleiman MK, Al-Mulla L (2007). Growing mangroves for enrichment of Kuwait's coastline - Guidelines and recommendations. Published by Kuwait Institute for Scientific Research, Kuwait. p. 18.

Boto K, Wellington J (1984). Soil Characteristics and Nutrient Status in a Northern Australian Mangrove Forest. Estuaries. 7(1):61-69.

Cintron G, Lugo AE, Martinez R (1985). Structural and functional properties of mangrove forests. In: The botany and Natural History of Panama. W.G. Darcy and M.D. Correa, eds.), Monogr. Syst. Bot. 10:53-66.

Donato DC, Kauffman JB, Murdiyarso D, Kurnianto S, Stidham M, Kanninen M (2011). Mangroves among the most carbon-rich forests in the tropics. Nature Geosci. 4:293-297. doi: 10.1038/ngeo1123.

Environment Agency of Abu Dhabi, EAD (2009). Climate change impacts, vulnerability and adaptation. Published by Environment Agency Abu Dhabi, United Arab Emirates. p. 197.

Environment Agency of Abu Dhabi, EAD (2011). Mangrove Forests In Environmental Atlas of Abu Dhabi Emirate. Published by Environment Agency of Abu Dhabi, United Arab Emirates. pp.54-55.

Environment Agency of Abu Dhabi, EAD (2013). Mangroves in UAE. https://www.abudhabi.ae/portal/public/en/citizens/safety-andenvironment/environment/mangroves-in-uae.

Eganathan P, Rao CR (2001). Manual on vegetative and micropropagation of mangroves. Published by M. S. Swaminathan Research Foundation, Chennai, India, p. 34.

English S, Wilkinson C, Baker V (1997). Survey manual for tropical marine resources, Chapter 3 Mangrove Survey, Australian Institute of Marine Science, Townsville, pp.119-196.

Fahn A (1979). Secretory tissues in plants. London: Academic Press.

FAO-RAP (2005). Report of the regional workshop on salt-affected soils from sea water intrusion: Strategies for rehabilitation and 
Management. 31 March to 1 April, 2005. Bangkok.

Feller IC, Whigham DF, McKee KM, O'Neill JP (2002). Nitrogen vs. phosphorus limitation across an ecotonal gradient in a mangrove forest. Biogeochem. 62:145:175.

Flowers TJ, Troke PF, Yeo AR (1977). The mechanism of salt tolerance in halophytes. Ann. Rev. Plant Physiol. 28:89-121.

Food and Agriculture Organization of the United Nations, FAO (2007). The World's Mangroves 1980-2005 (FAO Forestry Paper 153. FAO, 2007).

Food and Agriculture Organization of the United Nations, FAO (2008). Water Report of the United Arab Emirates. Retrieved from: http://www.fao.org/nr/water/aquastat/countries_regions/ARE/.

Fransworth E, Ellison AM (1997). The global conservation status of mangroves. Ambio 26:328-224.

Gill AM, Tomlinson PB (1975). Aerial roots. An array of forms and functions. Ch. 12 in The Development and functions of roots, eds. J. G. Torry.

Giri C, Ochieng E, Tieszen LL, Zue Z, Singh A, Loveland T, Masek J, Duke N (2010). Status and distribution of mangrove forests of the world using earth observation satellite data. Glob. Ecol. Biogeography. 20:1-6.

Hays MO, Gundlach ER (1979). Coastal processes field manual for oil spill management. Prepared for National Oceanic and Atmospheric Administration, Office of Marine Pollution Assessment. Boulder, Colorado, US and the Research planning Institute, Inc., South Carolina, US.

Kato S, Akarsone S (1998). Physiology and ecology of mangroves. Paper presented at the International Symposium on Mangrive Ecology and Biology. Kuwait Institute for Scientific Research. April 25-27, 1998. Kuwait.

Medina E (1999). Mangrove Physiology: The Challenge of Salt, Heat, and Light Stress under Recurrent Flooding. p. 109-126. In: A. YáñezArancibia y A. L. Lara- Domínguez (eds.). Ecosistemas de Manglar en América Tropical. Instituto de Ecología A.C. México, UICN/ORMA, Costa Rica, NOAA/NMFS Silver Spring MD, USA.

McKee KL (1993). Soil physicochemical patterns and mangrove species distribution - reciprocal effects. J. Ecol.81:477-487.

Ogino H (1993). Mangrove ecosystem as soil, water and plant interactive system. pp. 135-144. In H. Leith and A. Almasoum, eds., towards the rational use of salinity tolerant plants. Vol. 1. Kluwer Academic Publishers, the Netherlands.

Rabanal HR, Beuschel GK (1978). The mangroves and related coastal fishery resources in the United Arab Emirates. FAO, Rome.
Saenger P, Blasco F, Youseff A, Loughland R, Wrydani S (2001). The mangrove vegetation on the United Arab Emirates, with particular emphasis on those of Abu Dhabi Emirates. Proceedings of the International Symposium on Mangroves and Saltmarsh Ecosystems, 22-24 December 2001 Abu Dhabi, UAE, pp. 36-49.

Shahid SA (2012). Mangroves - Adaptation and occurrence, climate change and coastline protection. Farming Outlook. 11(3):26-31.

Shahid SA, Taha FK, Khalil M, Bhat NR (2004). Site selection criteria and characteristics for the introduction of mangrove in Kuwait. J. Facult. Sci. UAE University, 13:15-27.

Shriadah MMA (1999). Heavy metals in mangrove sediments of the United Arab Emirates shoreline (Arabian Gulf). Water, Air and Soil Pollution 116:523-534.

Snedaker SC, Smith SM, Biber PD, Araujo RJM (2001). Effect of oil emulsion on floating seedlings of Rhizophora mangle. In: Bhat, N. R., Taha, F. K., \& Al-Nasser, A., (eds). Mangroves ecosystems: Natural distributions biology and management. Kuwait Institute for Scientific Research, pp. 109-126.

Tam NFY, Wong YS (1998). Variations of soil nutrient and organic matter content in a subtropical mangrove ecosystem. Water Air Soil Pollut. 103:245-261.

Tam NFY, Wong YS, Lan CY, Wang LN (1998). Litter production and decomposition in a subtropical mangrove swamp receiving seawater. J. Exp. Marine Biol. Ecol. 226:1-18.

Troll W (1943). Vergleichende Morphologie den hoheren Pflanzen, bd. 1 t. 3, Vegetationsorgane. Berlin: Gebruder, Borntraeger.

Van Der Werf GR, Morton DC, Defries RS, Olivier JGJ, Kasibhatla PSM Jackson RB, Collatz GJ, Randerson JT (2009). $\mathrm{CO}_{2}$ emissions from forest loss. Nature Geosci. 2, 737-738

Vistro N (2010). Manual for raising mangrove container plants nurseries and mangrove plantation in the United Arab Emirates. Published by Environment Agency Abu Dhabi, United Arab Emirates. p. 52.

Waisel Y (1972). Biology of halophytes. New York: Academic Press. 